\title{
Improvement of Touch Sensitivity by Pressing
}

\author{
Hie-yong Jeong ${ }^{1}$, Mitsuru Higashimori², and Makoto Kaneko² \\ ${ }^{1}$ SAMSUNG Heavy Industries, ${ }^{2}$ Osaka University \\ ${ }^{1}$ Republic of Korea, ${ }^{2}$ Japan
}

\section{Introduction}

Human can perceive a touch sensation, when it is enough for the source of all touch information which is the spatial-temporal distribution of mechanical loads on the skin at the contact interface to get to be larger than the just noticeable difference (Srinivasan, 1996). If mechanical stimuli of external surroundings are smaller than the difference threshold, human cannot recognize any information of touch sensation during tactile exploration. The difference threshold is an important factor for evaluating the touch sensation, whereas it is well known that the just noticeable difference of human is easily affected according to physical environment as well as mental condition.

There have been a number of studies on finding factors to have an influence on a touch sensation (Johansson; Mountcastle; Bolanowski, 1983; 1972; 1982). Among various studies, especially we are interested in making sure whether the change of blood flow changes the touch sensitivity of human or not. Skin sympathetic nerve activity controls blood flow and sweating. Stimulation of skin sympathetic nerve activity causes vasoconstriction, which in turn decreases in skin blood flow. We have started to answer a question that the blood flow in the skin might alter physical property of skin and modify sensitivity of mechanosensitive receptors. However, the characteristic of blood flow is simply changed by mental as well as physical conditions. Accordingly, it is difficult to measure the touch sensitivity while getting the blood flow rate to be kept up with the settled amount in order to have a statistically meaningful data. The lack of information regarding the effect of skin blood flow on neurosensory mechanisms has been due to no appropriate measurement method.

To cope with this issue, our approach is to observe what happens when we compulsorily block the blood flow to the finger tip by pressing the proximal phalange of finger as shown in Fig. 1. Under such a condition the blood flow rate of fingertip can get to be kept up with a small and constant value. Fig. 1 shows a conceptual image of the experimental result how the touch sensitivity varies with respect to time. The goal of this work is to examine how the touch sensitivity alters under the pressed condition as shown in Fig. 1 through the weight discrimination test of non-invasive method. The sensory tissue will eventually get a serious damage after all for continuously pressing the finger. This situation will make us lose any touch sensitivity due to the necrosis. We would like to confirm whether the touch sensitivity temporarily increases and then decreases, or just start to decrease under the pressed condition. 
As a result of performed experiments, unexpectedly, we discovered that the touch sensitivity improves temporarily by approximately 3.6 times with the statistical significance test of below $0.1 \%$, when the proximal phalange of finger is pressed. That is, the human difference threshold is more sensitive than that before pressing. We believe that this is a discovery on how the human touch sensitivity changes under the pressed condition.

This work is organized as follows. In Section 2, we review related works. In Section 3, we show what experimental equipments are used for this main purpose, and then we describe the experimental results in detail in Section 4. In Section 5, we discuss the experimental results with measurement of skin physical property and vibrotactile perception thresholds, so that we can estimate which receptor mainly contributes to improving the touch sensitivity. Finally in Section 6, we conclude this work.

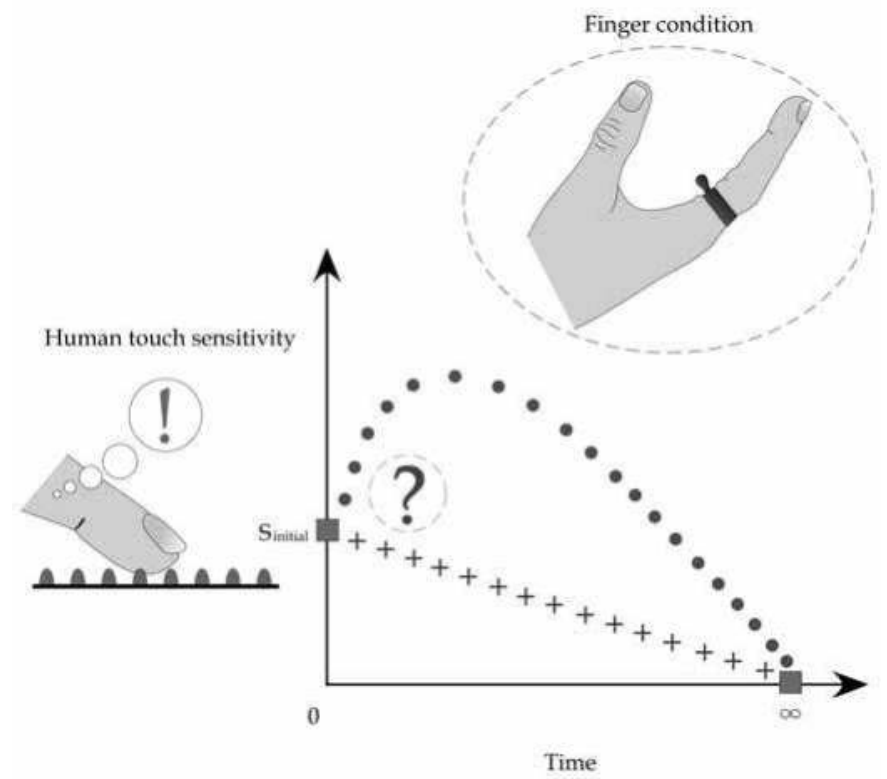

Fig. 1. Human touch sensitivity with respect to time after pressing.

\section{Related Works}

Johansson et al. have discovered the response characteristics and receptive field of skin mechanoreceptors when the human skin surface is stimulated by recording single cutaneous afferent fibres with the electrode (Johansson \& Vallbo, 1983). Srinivasan et al. have examined the relationship between the skin structure and mechanoreceptors, and then have shown that mechanoreceptors make the nerve impulse when the deformation of the skin surface exceeds the stimulus threshold (Srinivasan, 1996). On the other hand, Gaydos et al. have found that the significant decrement of finger dexterity performance is observed when the fingertip skin temperature goes down from the experimental result of the relationship between the skin temperature and the dexterity performance of the fingertip (Gaydos \& Dusek, 1958). Brajkovic et al. have shown experimentally that the finger dexterity is 
unaffected when the fingertip skin temperature is maintained between $28{ }^{\circ} \mathrm{C}$ through $35^{\circ} \mathrm{C}$ despite the decrement of the blood flow according to the temperature decrement in the experimental room (Brajkovic \& Ducharme, 2003). It has been indicated that not only the fingertip temperature but also the blood flow has an influence on the fingertip dexterity performance by these studies. However, although the fingertip touch sensitivity supports the dexterity performance, as far as we examined, there has been no study on the relationship between the human touch sensitivity and the blood flow.

\section{Experimental System}

\subsection{Definition of Human Touch Sensitivity}

In this work, the human touch sensitivity is defined as the percentage of correct answer that is measured by whether subjects wearing an eye mask can notice the difference or not, through the weight discrimination test based on Weber's Law.

\subsection{Experimental System}

Three kinds of experimental equipments in this paper are used as shown in Fig. 2; an instrument of weight discrimination test for measuring the human touch sensitivity, a noncontact point-typed stiffness sensor for measuring the fingertip stiffness according to the change of blood flow, and a laser tissue blood flow meter for monitoring the blood flow and mass.

The weight difference threshold based on Weber's Law is used for evaluating the touch sensitivity, Ernst Weber, the nineteenth century experimental psychologist, observed that the size of the difference threshold appears to be lawfully related to initial stimulus magnitude (Weber, 1978). This relationship based on Weber's Law can be expressed by:

$$
I=\frac{\Delta S}{S}
$$

where $\Delta S, S$, and $I$ express the difference threshold, the initial stimulus intensity, and the constant ratio despite variations in the $S$ term, respectively. For example, if the ratio is 0.05 , we can notice that the increment threshold for detecting the difference from $S=100 \mathrm{~g}$ is $\Delta S$ $=5 \mathrm{~g}$. When $S=200 \mathrm{~g}, \Delta S=10 \mathrm{~g}$ according to Equation. (1). Fig. 2 (a) shows an overview of the apparatus based on Weber's Law, where it is assembled with the slider to control the height, the test rod connected with the friction-free encoder from the slider, and the plate connected with the tip of the test rod in order to put on the weight, respectively. The different height according to the finger size of the subject is adjusted by monitoring the output of the encoder. The encoder is for making both the plate and the test rod horizontally. The probe contacting with the fingertip has the circular shape whose diameter is $5 \mathrm{~mm}$.

Fig. 2 (b) shows an overview of the non-contact point-typed stiffness sensor. This sensor consists of both the laser displacement sensor of OPTEX FA CO., LTD. and the air-pressure unit to control the airflow, respectively. The air-pressure unit is composed of an air nozzle and a high-speed electromagnetic valve to be able to make a switching motion with the maximum frequency of $500 \mathrm{~Hz}$. The laser beam for sensing the displacement passes through the inside of the air nozzle. It has a common axis between the air nozzle and the laser beam. 


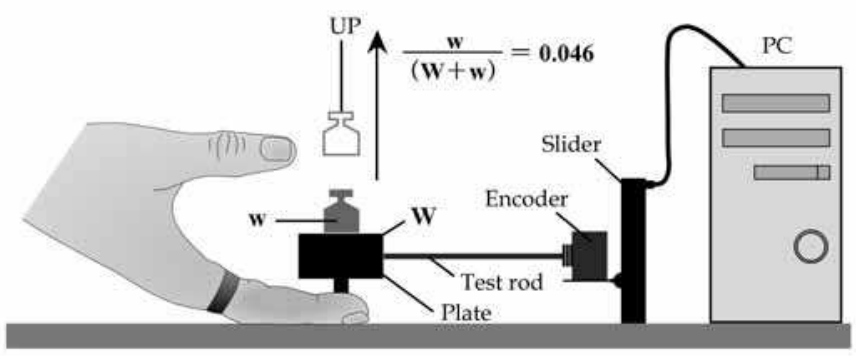

(a) Apparatus for measuring weight difference thresholds.

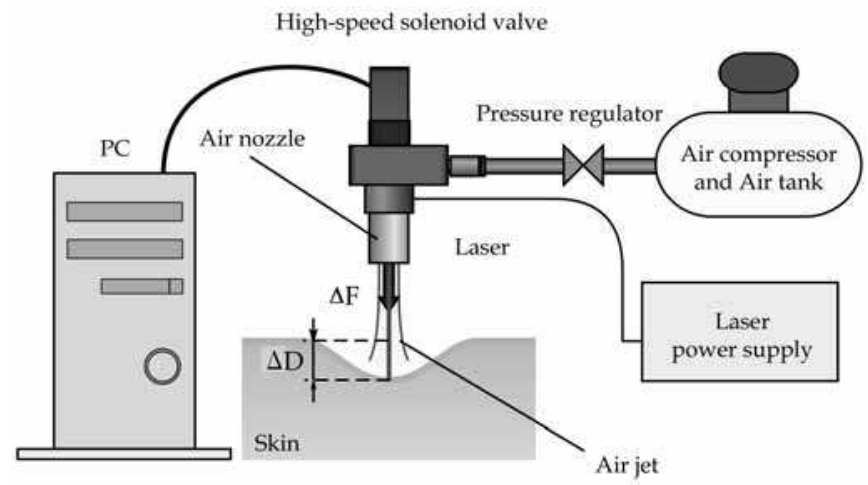

(b) Non-contact stiffness sensor.

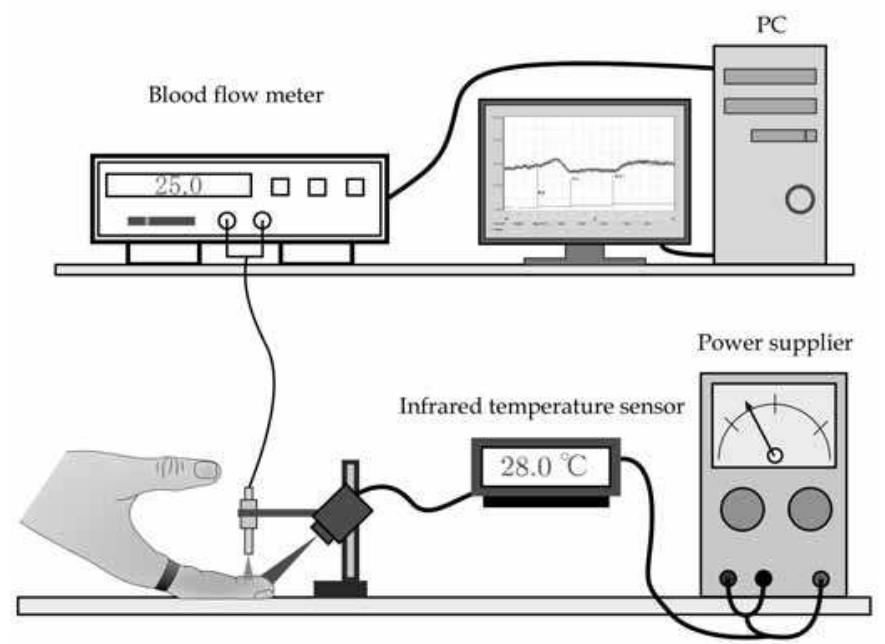

(c) Laser blood flow meter and infrared temperature sensor.

Fig. 2. Experimental system. 


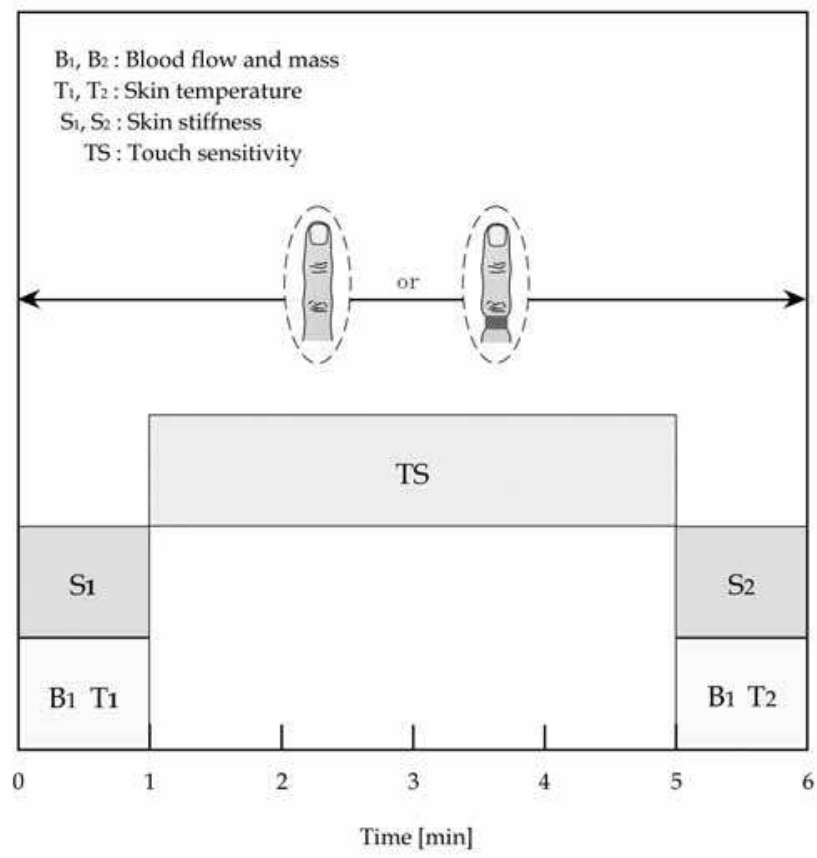

Fig. 3. Time schedule for experiments.

This mechanical configuration is for making the sensing point coincide with the force applying point at all time, so that we can achieve a consistent stiffness sensing for a deformable object like a human skin (Tanaka, 2007). We set the displacement between the laser sensor and human skin with $10 \mathrm{~mm}$ and the applied air force with $0.179 \mathrm{~N}$ during 200 ms. Then we can compute the average stiffness $K$ by obtaining the value of the laser displacement sensor by the following equation:

$$
K=\frac{\Delta F}{\Delta D}
$$

where $\Delta F$ and $\Delta D$ represent the change of force and skin surface displacement, respectively. As for the applied force, it is hard to measure the force during the stiffness measurement. Instead, we calibrate the force characteristic by changing the distance between the nozzle exit and the object in advance. We suppose that the pushing force by air is the function of the distance between the tip of nozzle and the surface of object.

Fig. 2 (c) shows a laser blood flow meter and an infrared temperature sensor. FLO-N1 of OMEGAWAVE, INC. as the blood flow meter is used to measure the accumulated mass of blood as well as the blood flow rate at the fingertip with the sampling time of $1 \mathrm{~ms}$. The length of laser wave is $780 \mathrm{~nm}$. The ultra-compact digital radiation temperature sensor of KEYENCE Corporation is used for examining the temperature. This sensor utilizes the set emissivity to convert the amount of received infrared radiation into temperature. 


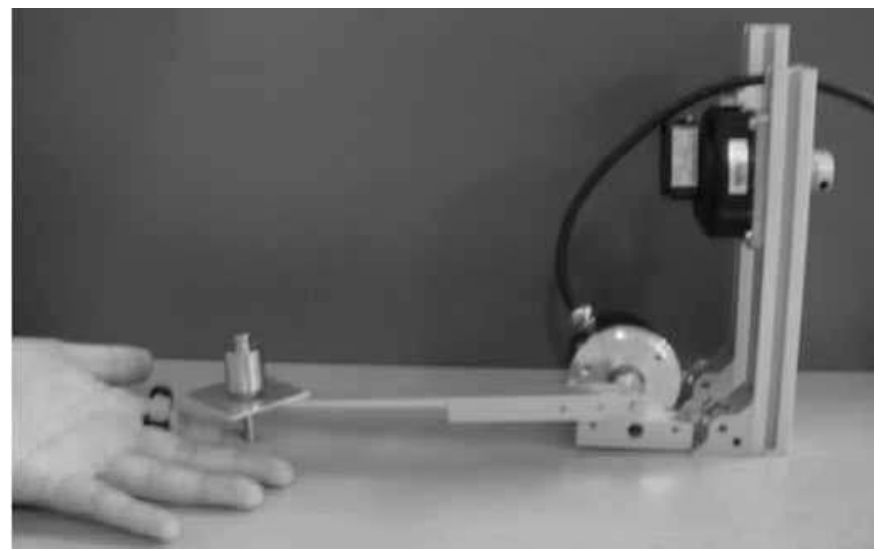

Fig. 4. An overview of experimental environment.

\section{Experiment}

\subsection{Experimental Method}

We first perform experiments under the non-pressed condition to obtain the touch sensitivity, the stiffness, the skin temperature, and the blood flow and mass at the time of zero. Then, we obtain three parameters under the pressed condition according to the time schedule as shown in Fig. 3. Fig. 4 shows an overview of weight discrimination test under the pressed condition. For acting a force on the fingertip, we put on the $103 \mathrm{~g}$ weight. The weight can be adjusted to load the $5 \mathrm{~g}$ weight on the plate and then the $5 \mathrm{~g}$ weight is lifted up. This test is done randomly 5 times/min, and totally 20 times during $4 \mathrm{~min}$, while each subject wears an eye mask. The ratio $I$ of Weber's Law is 0.046 . During the experiment under the pressed condition, we monitor how much blood flow is, while we start the experiment with roughly $30 \%$ of the blood flow under the non-pressed condition. All of subjects are 24 persons, the male with the age distribution of 21-25, where the blood flow rate under the non-pressed condition is $18 \pm 7 \mathrm{ml} / \mathrm{min} / 100 \mathrm{~g}$ and that under the pressed condition is $6 \pm 3 \mathrm{ml} / \mathrm{min} / 100 \mathrm{~g}$, respectively. We executed all experiments under the room temperature of $26^{\circ} \mathrm{C}$. The test point is the middle intersection of the distal phalange of the index finger of left hand.

\subsection{Experimental Results}

Fig. 5 shows the main result of this work to confirm how the touch sensitivity changes under the pressed condition, where each point is computed with the time average during every 1 min. The horizontal and the vertical axes denote the time and the touch sensitivity, respectively. As you can see from Fig. 5, when the proximal phalange of finger is pressed, unexpectedly, we found that the touch sensitivity is improved from $12 \%$ to $43 \%$ by approximately 3.6 times, while the continuous pressing results in the numbed finger because of the necrosis of sensory receptors. In other words, this result means that human under the pressed condition are able to perceive the smaller stimulus than that under the non-pressed condition because of the more sensitive discrimination threshold. These results are guaranteed with the statistical significance test ( $p$-value) of below $0.1 \%$. 
Fig. 6 shows the measured results of skin physical property with respect to time. Fig. 6 (a) shows the change of stiffness during the experiment. We would note that the stiffness is measured every $15 \mathrm{~s}$ during $1 \mathrm{~min}$ after pressing and before stopping the experiment as shown in Fig. 3. From Fig. 6 (a), we can see that the stiffness noticeably increases within $15 \mathrm{~s}$ under the pressed condition. Compared with that under the non-pressed condition, the fingertip stiffness under the pressed condition gets approximately 1.6 times harder than that under the non-pressed condition. We would note that the tendency is very reliable because the differences between two conditions are approved with the statistical significance test ( $p$ value) of below $0.1 \%$. This tendency comes from the accumulation of the blood mass at the fingertip. This fact of harder stiffness under the pressed condition can be proved by the experiment as shown in the appendix where the skin surface deformation is captured with an assistance of high-speed camera system. Fig. 6 (b) shows the change of fingertip skin temperature during experiment under the non-pressed and the pressed conditions. We can see that the skin temperature under the pressed condition just linearly decreases compared with that under the non-pressed condition. Fig. 6 (c) shows the change of the accumulated blood mass. As we expected, the accumulated blood mass increases at the fingertip under the pressed condition.

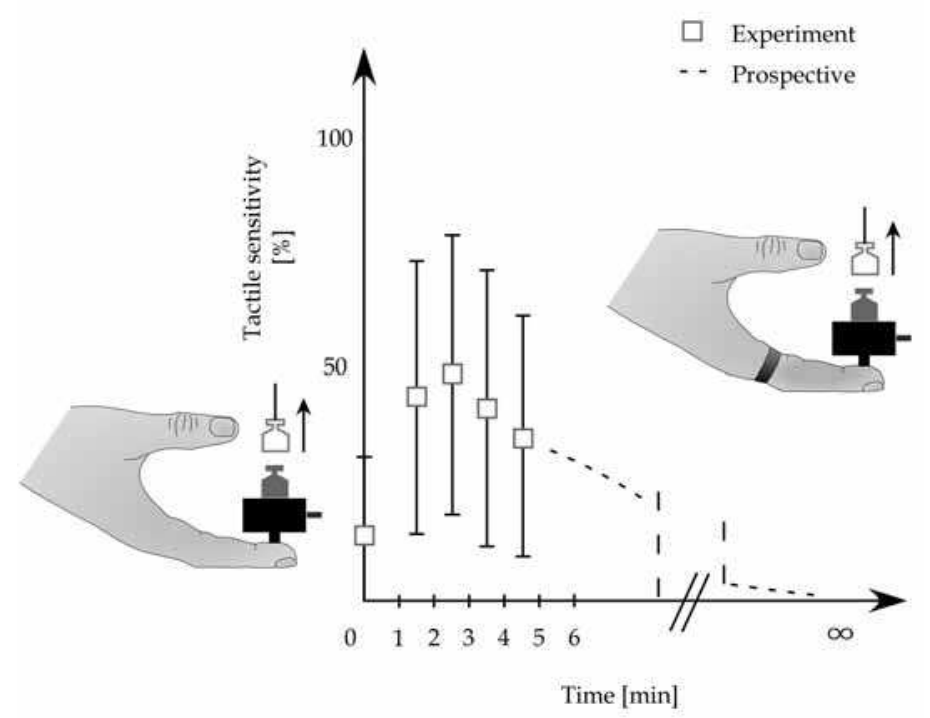

Fig. 5. Experimental results of touch sensitivity with respect to time.

\section{Discussion}

Fig. 7 shows two possible reasons why the touch sensitivity improves under the pressed condition. At the first route, in order to confirm the change of neural activity, we examine the touch sensitivity of other parts in finger. At first, we measure the point of A and B to 


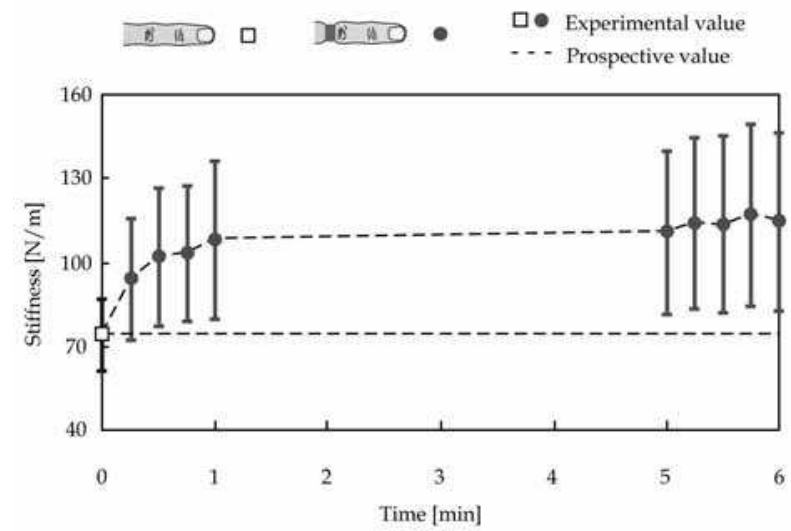

(a) Stiffness.

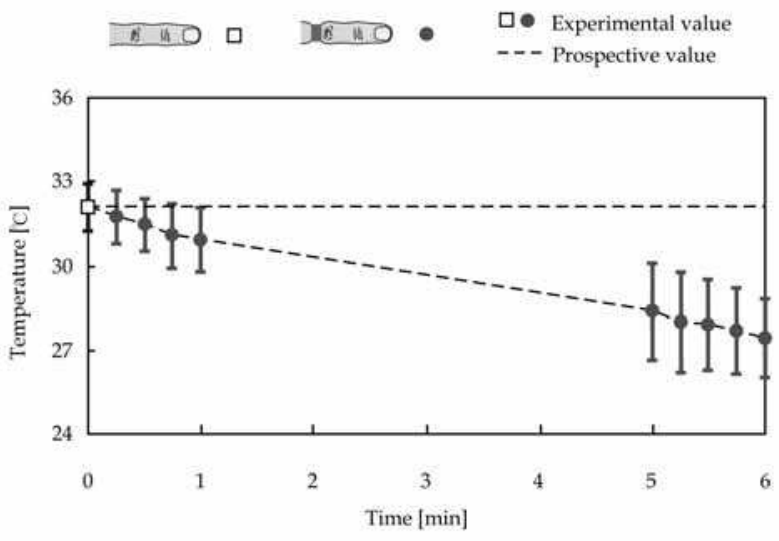

(b) Skin temperature.

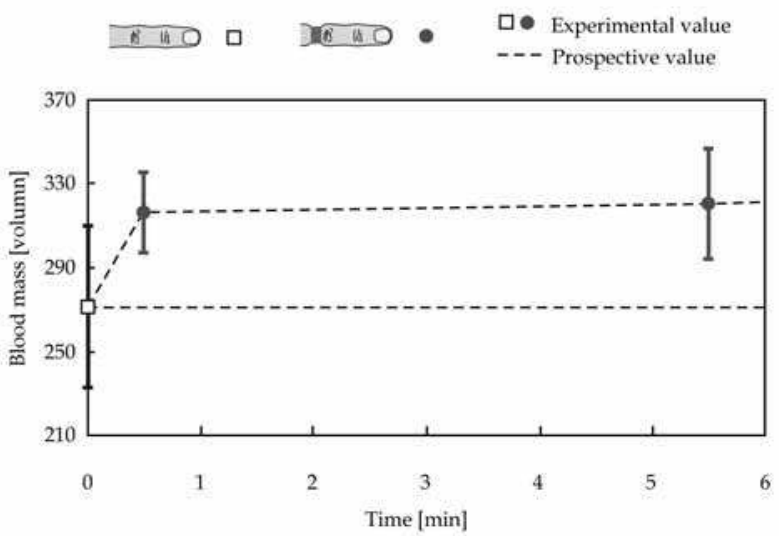

(c) Blood mass.

Fig. 6. Experimental results of skin physical property with respect to time. 


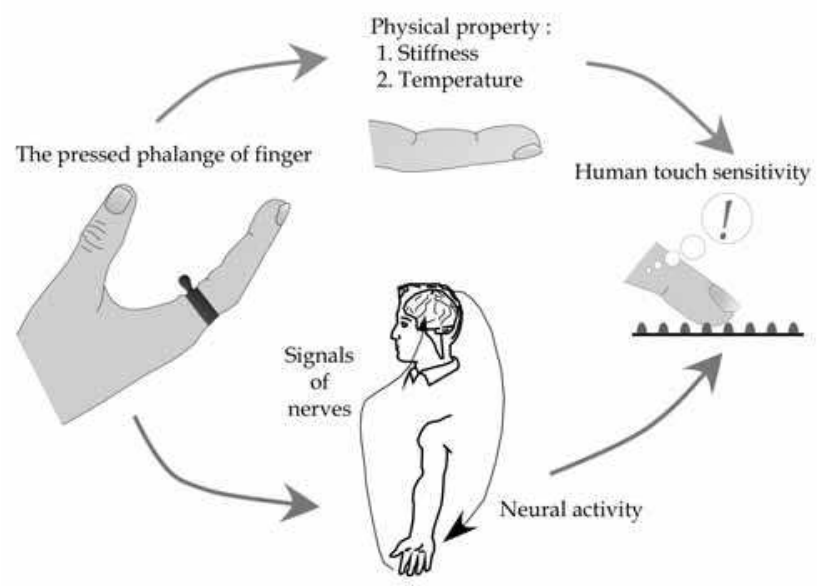

Fig. 7. Two possible routes on improving touch sensitivity under the pressed condition.

confirm whether the touch sensitivity improves or not when we execute the same experiment for the other part where mechanoreceptors have less distributed (Johansson \& Vallbo, 1983). As shown in Fig. 8 (a), there is no difference of touch sensitivity at two points, although the finger stiffness is changed with the significance test ( $p$-value) of below $1 \%$ as shown in Fig. 8 (b). Now, let us consider two cases which measure the middle finger by the same experiment under the non-pressed and the pressed index finger condition. If the neural route is more active under the pressed condition, we can expect that the touch sensitivity of other parts be also improved. According to the experiment in Fig. 8 (c), a small improvement can be observed for the touch sensitivity of the middle finger while the difference is not enough. This effect may be partially due to the effect of neural activity (Wallin, 1990).

Now, let us consider the change of physical property. It is well known that skin temperature is a factor to change the touch sensitivity (Hayward; Harazin; Nelson, 1986; 2007; 2004). Fig. 6 (b) shows the fingertip skin temperature with respect to time. From this result, we can see that it goes down linearly with respect to time under the pressed condition. However, as you can see from Fig. 5 and Fig. 6 (b), it is difficult for the skin temperature to affirm only to make an influence on the touch sensitivity. This is because the touch sensitivity is changed with the time constant of $20 \mathrm{~s}$ under the pressed condition, although the skin temperature shows almost linearly decreasing. This could suggest that another factor except the skin temperature works the change of the touch sensitivity. Let us now consider the relationship between the fingertip stiffness and the touch sensitivity with respect to time. From Fig. 5 and Fig. 6 (a), we can see that the change patterns of both results are similar each other with respect to time, especially in the initial phase under the pressed condition. There have been a couple of reports where the fingertip stiffness affects the touch sensitivity (Dellon, 1995; 1981; 1978). We believe that the increase of fingertip stiffness under the pressed condition makes the increase of touch sensitivity.

In order to explain results appropriately, it is important to examine the frequency response of sensory cell in the fingertip skin. It is well known that there are four kinds of mechanoreceptors, Ruffini ending (below $10 \mathrm{~Hz}$ ), Merkel cell (below $10 \mathrm{~Hz}$ ), Meissner 
corpuscle $(20-40 \mathrm{~Hz}$ ), and Pacinian corpuscle (over $40 \mathrm{~Hz}$ ) in fingertip (Johansson; Mountcastle; Bolanowski; Bolanowski, 1983; 1972; 1982; 1984). Each receptor has

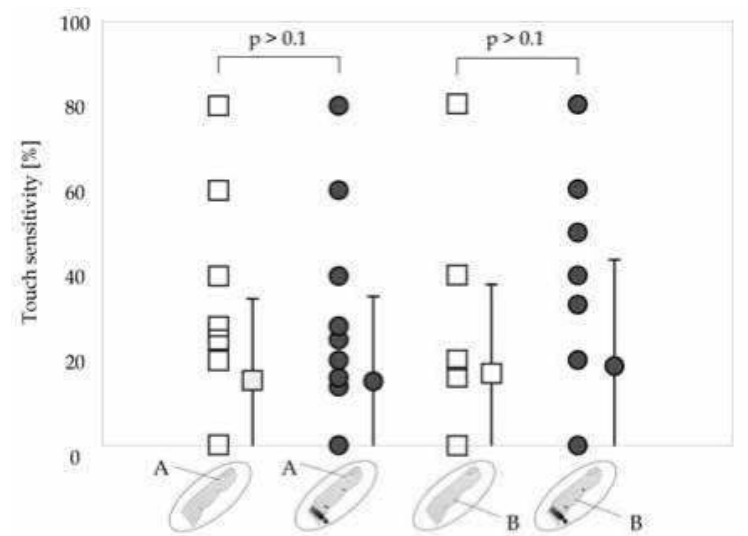

(a) Touch sensitivity at the point of $\mathrm{A}$ and $\mathrm{B}$.

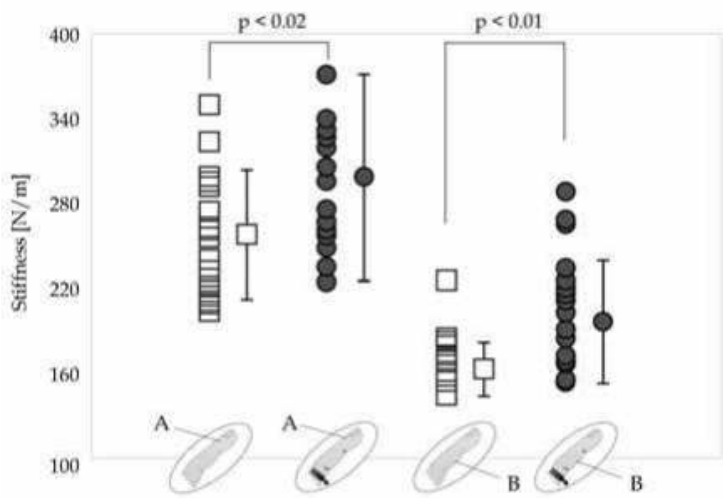

(b) Stiffness at the point of $\mathrm{A}$ and $\mathrm{B}$.

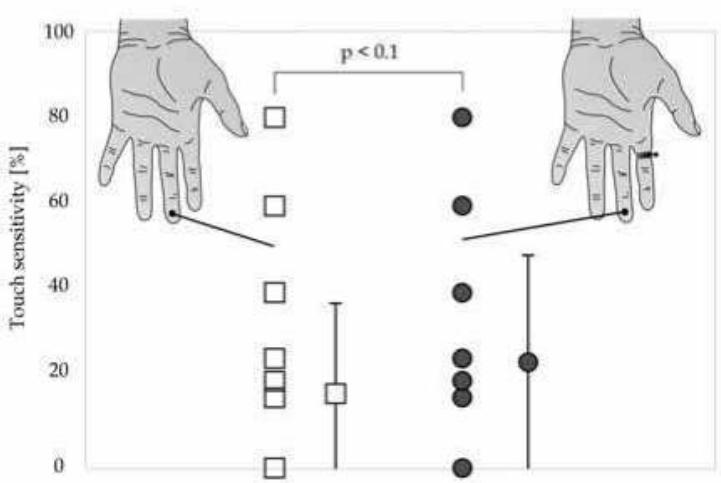

(c) Touch sensitivity at the middle finger under two different conditions.

Fig. 8. Touch sensitivity of the other part finger. 


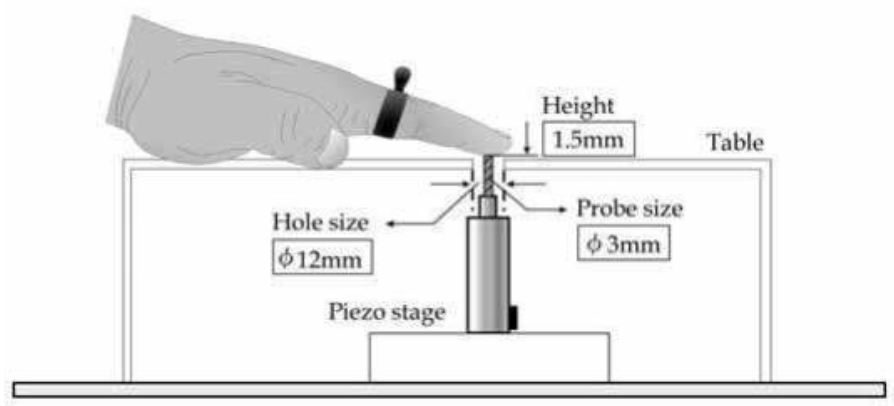

Fig. 9. Apparatus for measuring vibrotactile perception thresholds.

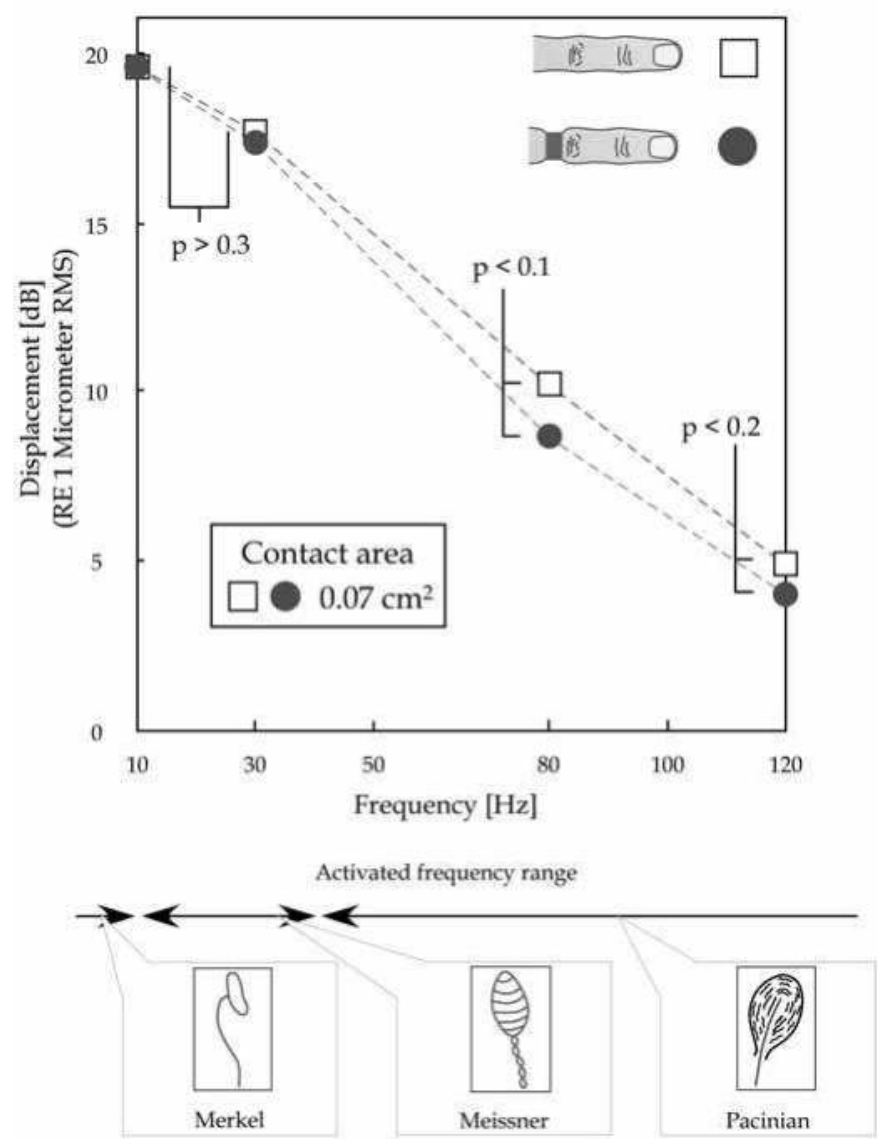

Fig. 10. Experimental results of vibrotactile perception thresholds.

individual different frequency characteristic. In order to evaluate the frequency characteristic of touch sensitivity, we examined vibrotactile perception thresholds by using 
the probe whose frequency and amplitude are controllable as shown in Fig. 9 where an active rod made by MESS-TEK Corporation is used. Through experiments, we found an interesting result where the vibrotactile perception threshold is done for the frequency of 80$120 \mathrm{~Hz}$ where the Pacinian corpuscle is working dominantly. Fig. 10 explains these results where the dotted line and the one-point dotted line are referred by (Verrillo, 1962; 1963). No statistically significant effect is found on the response of Merkel's and Meissner's mechanoreceptors to vibration stimuli at the frequency of $10 \mathrm{~Hz}$ and $30 \mathrm{~Hz}$, and also Ruffini receptors can be excluded for this study because this sensory is revealed to activate for the stretch force of skin. According to these experimental results, it must be the proper evaluation that Pacinian receptors get more sensitive under the pressed condition compared with the response characteristic of the non-pressed condition. This hypothesis makes sense, since the contact force can transmit to the Pacinian corpuscle more directly through a harder tissue caused by the blocked blood. In order to really make sure, we need to adopt the invasive method for assuring our results, which is the way looking into the response with piercing the stimulus probe to mechanoreceptors directly (Toma \& Nakajima, 1995).

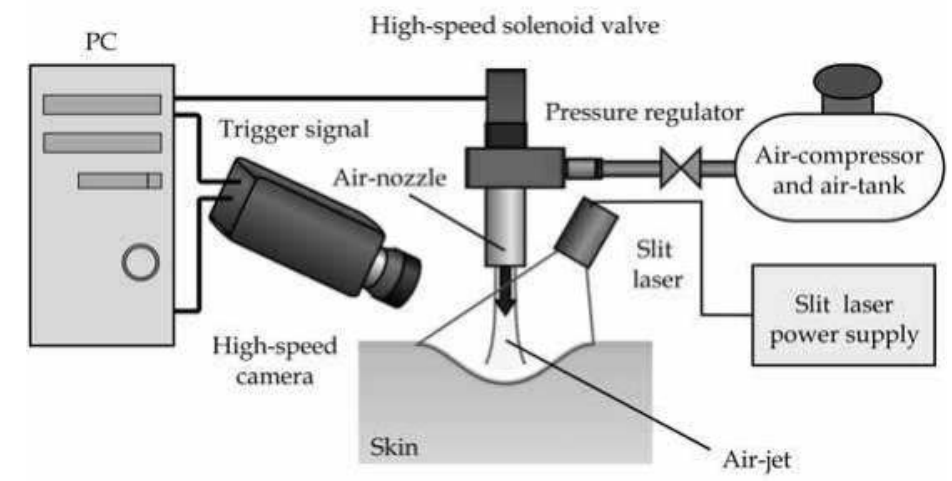

Fig. 11. High-speed camera system.

\section{Conclusion}

We performed how the touch sensitivity was changed under the pressed condition through the weight discrimination test based on Weber's Law for 24 subjects. Based on these experiments, we concluded this paper as follows.

1) We discovered that the touch sensitivity improved temporarily when the proximal phalange of finger was bound and pressed.

2) We also confirmed that the accumulated blood caused the stiffness of fingertip to get to be harder, and found that the tendency of touch sensitivity was similar to that of fingertip stiffness while skin temperature was decreased linearly.

3) Through the vibrotactile perception threshold, we suggested that the Pacinian corpuscle be a candidate to bring about the improvement of touch sensitivity under the pressed condition.

We would like to investigate the responsiveness of mechanoreceptors in the glabrous skin of the fingertip to vibratory stimuli by using a microneurographic technique under the pressed condition when the frequency and applied pressure to the skin are varied in the future. 


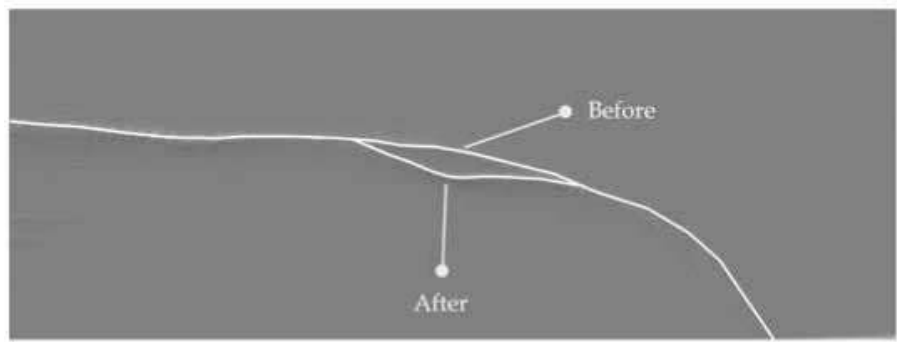

(a) Under the non-pressed condition.

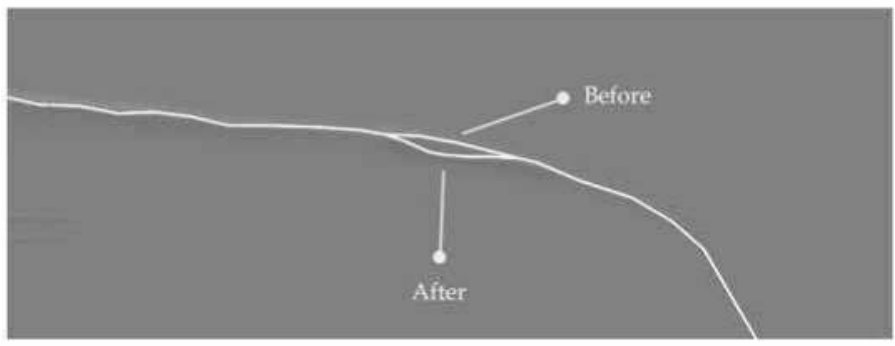

(b) Under the pressed condition.

Fig. 12. Captured deformation by a high-speed camera.

\section{References}

Srinivasan, M.A. \& Dandekar, K. (1996). Journal of Biomechanical Engineering, Vol.118, 48-55. Johansson, R.S. \& Vallbo, A.B. (1983). Trends in Neuroscience, Vol.6, 27-32.

Mountcastle, V.B.; LaMotte, R.H. \& Carli, G. (1972). Journal of Neurophysiology, Vol.35, 122136.

Bolanowski, S.J. \& Verrillo, R.T. (1982). Journal of Neurophysiology, Vol.48, 836-855.

Bolanowski, S.J. \& Zwislocki, J.J. (1984). Journal of Neurophysiology, Vol.51, 793-811.

Gaydos, H.F. \& Dusek, E.R. (1958). Journal of Applied Physiology, Vol.12, 377-380.

Brajkovic, D. \& Ducharme, M.B. (2003). Journal of Applied Physiology, Vol.95, 758-770.

Weber, E.H. (1978). Academic Press, ISBN-13: 978-0127405506, New York.

Tanaka, N. \& Kaneko, M. (2007). Direction Dependent Response of Human Skin, Proceedings of International Conference of the IEEE Engineering in Medicine and Biology Society, pp. 1687-1690, Lyon, France, August 2007.

Johansson, R.S. \& Vallbo, A.B. (1983). Trends in Neuroscience, Vol.6, 27-32.

Wallin, B.G. (1990). Journal of the Autonomic Nervous System, Vol.30, 185-190.

Hayward, R.A. \& Griffin, J. (1986). Scandinavian Journal of Work Environment and Health, Vol.12, 423-427.

Harazin, B. \& Harazin-lechowska, A. (2007). International Journal of Occupational Medicine and Environmental Health, Vol.20, 223-227.

Nelson, R.; Agro, J.; Lugo, E. ; Gasiewska, H.; Kaur, E.; Muniz, A.; Nelson, A. \& Rothman, J. (2004). Electromyogr. Clin. Neurophysiol, Vol.44, 209-216. 
Dellon, E.S.; Keller, K.; Moratz, V. \& Dellon, A.L. (1995). The Journal of Hand Surgery, Vol.20B, No.1, 44-48.

Dellon, A.L. (1981). Baltimore, Williams and Wilkins.

Dellon, A.L. (1978). Journal of Hand Surgery, Vol.3, No.5, 474-481.

Verrillo, R.T. (1962). The Journal of the Acoustical Society of America, Vol.34, No.11, 1768-1773.

Verrillo, R.T. (1963). The Journal of the Acoustical Society of America, Vol.35, No.12, 1962-1966.

Toma, S. \& Nakajima, Y. (1995). Neuroscience Letters, Vol.195, 61-63.

\section{Appendix}

In order to observe the skin surface deformation under the pressed condition compared with that under the non-pressed condition, we set up the high-speed camera system as shown in Fig. 11. Fig. 12 shows the result of the skin surface deformation where Fig. 12 (a) and (b) are under the non-pressed and the pressed condition, respectively. The "Before" and "After" in Fig. 12 denote the surface profiles before and after the force impartment, respectively. The finger deformation during the force impartment is obtained by chasing the slit laser with an assistance of the high-speed camera. The result provides us with the sufficient information on the deformation under both conditions, compared with the pointtyped stiffness sensor. An interesting observation is that the deformed shape keeps the similarity between two conditions. This means that the deformation in the lateral direction due to the force impartment is proportional to the deformation in the depth direction. Through Fig. 12, we can confirm that the diameter of deformed area under the pressed condition is almost 2 times less than that under the non-pressed condition for this particular experiment.

\section{Acknowledgment}

This work was supported by 2007 Global COE (Centers of Excellence) Program $\lceil$ A center of excellence for an In Silico Medicine」 in Osaka University. 


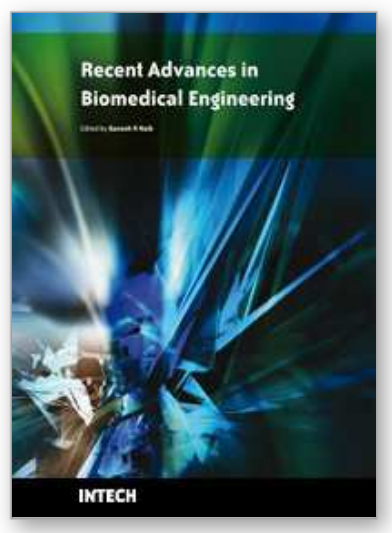

\author{
Recent Advances in Biomedical Engineering \\ Edited by Ganesh R Naik
}

ISBN 978-953-307-004-9

Hard cover, 660 pages

Publisher InTech

Published online 01, October, 2009

Published in print edition October, 2009

The field of biomedical engineering has expanded markedly in the past ten years. This growth is supported by advances in biological science, which have created new opportunities for development of tools for diagnosis and therapy for human disease. The discipline focuses both on development of new biomaterials, analytical methodologies and on the application of concepts drawn from engineering, computing, mathematics, chemical and physical sciences to advance biomedical knowledge while improving the effectiveness and delivery of clinical medicine. Biomedical engineering now encompasses a range of fields of specialization including bioinstrumentation, bioimaging, biomechanics, biomaterials, and biomolecular engineering. Biomedical engineering covers recent advances in the growing field of biomedical technology, instrumentation, and administration. Contributions focus on theoretical and practical problems associated with the development of medical technology; the introduction of new engineering methods into public health; hospitals and patient care; the improvement of diagnosis and therapy; and biomedical information storage and retrieval. The book is directed at engineering students in their final year of undergraduate studies or in their graduate studies. Most undergraduate students majoring in biomedical engineering are faced with a decision, early in their program of study, regarding the field in which they would like to specialize. Each chosen specialty has a specific set of course requirements and is supplemented by wise selection of elective and supporting coursework. Also, many young students of biomedical engineering use independent research projects as a source of inspiration and preparation but have difficulty identifying research areas that are right for them. Therefore, a second goal of this book is to link knowledge of basic science and engineering to fields of specialization and current research. The editor would like to thank the authors, who have committed so much effort to the publication of this work.

\title{
How to reference
}

In order to correctly reference this scholarly work, feel free to copy and paste the following:

Hie-yong Jeong, Mitsuru Higashimori and Makoto Kaneko (2009). Improvement of Touch Sensitivity by Pressing, Recent Advances in Biomedical Engineering, Ganesh R Naik (Ed.), ISBN: 978-953-307-004-9, InTech, Available from: http://www.intechopen.com/books/recent-advances-in-biomedicalengineering/improvement-of-touch-sensitivity-by-pressing

\section{INTECH}

open science | open minds

\section{InTech Europe}

University Campus STeP Ri

Slavka Krautzeka 83/A

\section{InTech China}

Unit 405, Office Block, Hotel Equatorial Shanghai

No.65, Yan An Road (West), Shanghai, 200040, China 
51000 Rijeka, Croatia

Phone: +385 (51) 770447

Fax: +385 (51) 686166

www.intechopen.com
中国上海市延安西路65号上海国际贵都大饭店办公楼 405 单元

Phone: +86-21-62489820

Fax: $+86-21-62489821$ 
(C) 2009 The Author(s). Licensee IntechOpen. This chapter is distributed under the terms of the Creative Commons Attribution-NonCommercial-ShareAlike-3.0 License, which permits use, distribution and reproduction for non-commercial purposes, provided the original is properly cited and derivative works building on this content are distributed under the same license. 